ANUVA Volume 2 (2): 127-135, 2018

Copyright (C2018, ISSN: 2598-3040 online

Available Online at: http://ejournal.undip.ac.id/index.php/anuva

\title{
Literasi Media Pada Digital Native Kota Semarang
}

\author{
Yuli Rohmiyati ${ }^{*}$ ) \\ ${ }^{I}$ Prodi Ilmu Perpustakaan, Fakultas Ilmu Budaya, Universitas Diponegoro \\ Jl. Prof. Soedarto, SH, Kampus Tembalang, Semarang. Indonesia \\ *)Korespondensi : yulirohmiyati@gmail.com
}

\begin{abstract}
The purpose of this study is to find out how the role of parents in digital media literacy native. The method used is descriptive method. Parents' role in accompanying digital native children in using media / mobile phones in terms of surveillance, agreement making, and mentoring about any material accessible to children. The characters that appear in the digital native children in Rusunawa Sawah Besar Kota Semarang become responsible, open, communicative.
\end{abstract}

Key Words: Media Literacy, Parents, Digital native, Semarang City.

\begin{abstract}
Abstrak
Tujuan dari penelitian ini adalah untuk mengetahui bagaimana peran orang tua dalam literasi media digital native. Metode penelitian yang digunakan adalah metode deskriptif. Peran Orang tua dalam mendampingi anak-anak digital native dalam menggunakan media/ ponsel dalam hal pengawasan, pembuatan kesepakatan2, dan pendampingan ttg materi apa saja yang diakses oleh anak-anak. Karakter-karakter yang muncul pada anak-anak digital native di Rusunawa Sawah Besar Kota Semarang menjadi bertanggung jawab, terbuka, komunikatif.
\end{abstract}

Kata kunci : Literasi media, Orang tua, Digital native, Kota Semarang.

\section{Pendahuluan}

Kehadiran teknologi informasi dan komunikasi di Indonesia menjadi luar biasa saat mampu meningkatkan kinerja di berbagai sektor. Namun, teknologi informasi tersebut tampaknya belum seiring dengan kemampuan masyarakat Indonesia untuk menerima hal tersebut, terutama bagi kaum anak-anak dan orang tua. Fenomena cyber bullying, kecanduan bermain games, gangguan psikologis, kemerosotan prestasi anak adalah beberapa dampak buruk yang memprihatinkan para orang tua. Kapasitas literasi media, tampaknya menjadi kemampuan yang wajib dimiliki seorang orang tua. Keberadaan bimbingan orang tua untuk menggunakan media sangat dorang tuatuhkan. Kontrol aktif merupakan hal yang dilakukan saat anak mengonsumsi media seperti televisi, ponsel, dan komputer.

Literasi media dibangun dari struktur pengetahuan, yang kemudian dijadikan dasar keterampilan dan informasi yang membentuk kontrol individu memaknai media. Artinya, setidaknya orang tua memiliki sekumpulan pengetahuan baik dalam area media dan teknologi. Lima area meliputi dampak 
media, isi media, industri media, pemahaman dunia nyata dan diri sendiri. Perempuan sebagai orang tua, memiliki berbagai peran dan tanggungjawab yang multidimensi. Salah satu peran yang diamanahkan Tuhan adalah menjadi seorang orang tua pendidik. Penekanan peran orang tua untuk literasi media anak menjadi penting, mengingat posisi orang tua di sebagian besar masyarakat kita berada di sektor non publik, selebihnya tetap di lingkungan domestik saja, yakni menjadi orang tua rumah tangga.

Oleh karena itu, kesadaran bahwa si anak merupakan digital native, menuntut orang tua rumah tangga yang berperan aktif melakukan kontrol terhadap media. Diperlukan regulasi teknologi informasi dan komunikasi yang dimaksudkan untuk meningkatkan derajat kemuliaan seseorang. Regulasi tersebut tidak akan berjalan tanpa aplikasi berarti dari pihak keluarga. Orang tua merupakan pihak pendamping sang anak, sekaligus pendidik terdekat bagi mereka.

Monitoring sebagai upaya penerapan literasi media tidak selalu berada dalam wujud fisik, yakni kehadiran sang orang tua mutlak. Bagi orang tua yang bekerja dengan mobilitas yang intensif, misalnya bekerja di sektor publik, tidak serta merta melupakan perhatian pada kebutuhan ini. Orang tua dapat mengontrolnya dengan membuat setting pada teknologi media yang dipakai, maupun aturan yang dorang tuaat secara internal dalam keluarga.

Kenyataan kini dan masa depan, orang tua adalah orang tua yang menghadapi seorang anak digital native, yakni generasi muda yang berada di era digital. Digital native adalah kelompok yang saat mulai belajar dan sudah mengenal internet atau yang saat ini berada di bawah 24 tahun.Mereka memerlukan pola asuh berbeda dan istimewa.

Digital native memiliki beberapa ciri khas yang membedakannya dengan generasi sebelumnya, setidaknya dalam hal-hal berikut ini: Pertama, digital native cenderung rorang tuat soal identitas. Mereka begitu peduli dengan ke"ada"an diri mereka. Karena itulah mereka ramai-ramai membuat akun di Facebook, Twitter dan Youtube untuk membuktikan kepada dunia bahwa mereka ada. Kenarsisan ini menjadi wajar karena mereka memang menemukan media yang bisa memuaskan hasrat mereka untuk eksis.

Kedua, privasi. Generasi digital native cenderung lebih terbuka, blak-blakan, dan open minded. Jika mereka bilang suka, mereka bilang suka, dan jika tidak suka, mereka akan bilang tidak suka. Mereka juga merasa tidak masalah "membuka" apa yang disebut oleh generasi sebelum mereka sebagai privasi. Mereka malah berlomba-lomba membuka kehidupan privasi mereka di status Facebook dengan menulis “@ mall X bareng temen”, "sedih banget karena baru putus", "mau tidur", dan lain-lain. Tetapi sebaliknya, jika orang tua menanyakan tentang pemakaian ponsel mereka atau sekedar menyentuh ponsel mereka maka mereka akan berteriak jangan disentuh karena ponsel adalah privasi mereka.

Ketiga, kontrol dan kebebasan. Generasi digital native gila kebebasan. Mereka tidak suka diatur dan dikekang. Mereka ingin memegang kontrol, dan internet menawarkan hal itu. Jika mereka tidak suka suatu website, mereka bisa menutupnya saat itu juga. Mereka juga bebas untuk menolak atau menerima permintaan pertemanan di Facebook. Sebaliknya, jika mereka mendukung sesuatu, mereka akan 
berbondong-bondong mendukungnya dengan fanatik seperti pada kasus Prita dan Bibit-Chandra. Jika ingin sukses berhubungan dengan generasi digital native, sederhana. Duduk bersama mereka, libatkan untuk berpartisipasi. Buat tujuan bersama-sama mereka dan minta saran kritik dari mereka. Biarkan mereka mengambil keputusan.

Keempat, proses belajar. Generasi digital native jengah ketika disuruh membaca Encyclopedia Brittanica, tapi toh mereka tahu banyak hal. Hal ini bisa terjadi karena mereka selalu berpacaran dengan Google dan search engine lain. Kemampuan belajar mereka jauh lebih cepat karena segala informasi ada di ujung jari mereka. Dengan mengetahui kecenderungan beberapa karakter Generasi digital native, kita mungkin tidak akan heran lagi mengapa pertumbuhan Facebook, You Tube, dan Twitter begitu cepat sehingga terasa "mengerikan." Karena di situs-situs itulah Generasi digital native menemukan diri mereka. Di sana mereka bisa narsis, eksis, dan menjadi diri mereka sendiri. Mereka juga mempunyai kebebasan dan kontrol. Di sana mereka bisa berbagi notes Facebook, link bermutu di Twitter, ataupun video inspiratif di Youtube. Sementara situs-situs yang tidak menghidupkan karakter Generasi digital native akan habis digilas gelombang ini.

Kehadiran generasi digital native, tidak bisa dipungkiri lagi. Perhatian masyarakat perlu ditanamkan pada literasi media, dan dimulai dari institusi keluarga. Dengan demikian, generasi mendatang merupakan generasi kuat yang menyadari bahwa teknologi informasi tidak menjadikan nilai kebangsaan dan intelektual mereka terkikis. Namun, membuat mereka semakin dekat dengan peradaban.

Permasalahan adalah kurangnya komunikasi orang tua dan anak yang disebabkan karena penggunaan teknologi yang mengarah pada sikap egois, individual dan kurang peka terhadap lingkungan sekitar dapat mengikis sikap kebangsaan yang akan tergantikan dengan sikap egois, individual dan bebas. Apalagi jika kita melihat kehidupan di Rusunawa, yang mana di Rusunawa tersebut merupakan rumah susun sederhana sewa yang diperuntukan bagi masyarakat menengah ke bawah. Di rusunawa Sawah Besar sebagian orang tua-orang tua sorang tuak dengan pekerjaannya sehingga anak-anaknya kurang mendapat pengawasan dalam penggunaan teknologi.

\section{A. Rumusan Masalah}

Dari latar belakang yang telah diuraikan, maka rumusan masalah dalam penelitian ini adalah bagaimana peran orang tua dalam mendampingi anak-anak digital native dalam menggunakan media?

\section{B. Tujuan Penelitian}

Tujuan yang ingin dicapai dalam penelitian ini adalah untuk menganalisis bagaimana peran orang tua dalam mendampingi anak-anak digital native dalam menggunakan ponsel. 


\section{Manfaat Penelitian}

Manfaat penelitian ini adalah:

Secara teoritis : Menemukan bentuk-bentuk peran orang tua dalam pendampingan literasi media untuk anak-anak dalam menumbuhkan karakter kebangsaan.

Secara praktis : Mengurangi dampak negatif dari penggunaan dan pemanfaatan teknologi dan ikut menumbuhkan karakter kebangsaaan yang mulai terkikis.

\section{Landasan Teori}

\section{A. Literasi Media}

Media adalah perangkat komunikasi massa, semata-mata demi alasan kemudahan saja. Namun dalam kaitannya dengan media literacy, media dimaknai sebagai: (1) Alat dan materi untuk mentransmisikan informasi; (2) Medium untuk merekam dan melindungi informasi; (3) Informasi atau pesan-pesan yang didistrorang tuasikan di media.

Media literacy dikonsepkan sebagai "...the ability to access, analyse, evaluate and create messages across a variety of contexts (Livingstone, 2003)." Wikipedia, the free encyclopedia, menyebutkan bahwa media literacy adalah ketrampilan untuk memahami sifat komunikasi, khususnya dalam hubungannya dengan telekomunikasi dan media massa. Konsep ini diterapkan pada beragam gagasan yang berupaya untuk menjelaskan bagaimana media menyampaikan pesan-pesan mereka, dan mengapa demikian. Rubin dalam Prihandini (2007) menjelaskan tiga definisi media literacy. Pertama, kemampuan mengakses, menganalisis, mengevaluasi dan mengkomunikasikan pesan. Kedua, yaitu pengetahuan tentang bagaimana fungsi media dalam masyarakat. Ketiga, yaitu memahami budaya, ekonomi, politik dan pemaksaan teknologi dalam menciptakan, memperoduksi dan mentransmisi pesan.

Konsep media literacy pertama kali diperkirakan muncul pada tahun 1980an, dan kini telah menjadi standar topik kajian di sekolah-sekolah berbagai negara. Secara logis dapat dipahami, konsep ini tidak muncul dari kalangan media, melainkan dari para aktivis dan akademisi yang peduli dengan dampak buruk media massa yang dikendalikan oleh kekuatan-kekuatan kapitalis hingga menafikan kepentingan publik. Pemikiran sejumlah tokoh komunikasi-filosof terkemuka memicu lahirnya konsep media literacy. Sonia Livingstone (2004) mencatat sosok-sosok seperti teorisi komunikasi Kanada Marshall McLuhan, ahli linguistik Kritis Amerika Noam Chomsky, filosof Prancis Jean Baudrillard, kritikus komunikasi Amerika Serikat Neil Postman, dan perintis media education Amerika: Renee Hobbs.

Landasan teoritis media literacy sendiri bersumber dari tradisi pemikiran kiri, yang berkembang dalam cultural studies (Leftist Cultural Studies). Seperti diungkapkan Livingstone (2004), media literacy adalah "... a synthesizer of media education projects dating back to 1920 s ... act as an umbrella term for teaching practices that make students aware of the construct of mass media." Media literacy kerap disalahkaprahkan dengan media education. Sesungguhnya, media literacy perlu dibedakan pengertiannya 
dari media education. Media literacy bukanlah media education, kendati yang terakhir ini kerap menjadi bagian dari yang pertama. Media education memandang media dalam fungsi yang senantiasa positif, yaitu sebagai a site of pleasure dalam berbagai bentuk. Sedangkan media literacy yang memakai pendekatan inocculationist berupaya memproteksi anak-anak dari apa yang dipersepsi sebagai efek buruk media massa.

Penggunaan media dan produk media sebagai bagian dari proses belajar mengajar, misalnya mempelajari cara memproduksi film independen atau menggunakan suratkabar sebagai sumber penelusuran data, tergolong dalam media education. Adapun media literacy bergerak lebih jauh dari itu. Dengan pendekatan yang lebih kritis, media literacy tidak hanya mempelajari segi-segi produksi, tetapi juga mempelajari kemungkinan apa saja yang bisa muncul akibat kekuatan media. Media literacy mengajari publik memanfaatkan media secara kritis dan bijak (Astuty, 2007).

Sementara itu Silverblatt's (dalam Baran 2012) mendefinikan lima elemen media literacy; 1) Kesadaran akan dampak media massa pada individu dan masyarakat, 2) pemahaman terhadap proses komunikasi massa, 3) Pengembangan strategi untuk menganalisis dan mendiskusikan pesan media, 4) Kesadaran isi media sebagai teks yang memberikan masukan bagi budaya kontemporer dan diri kita, 5) Pengolahan rasa senang kepada media, pemahaman dan penghargaan akan isi media. Elemen-elemen kunci dalam literasi media adalah literasi media tidak terbatas pada satu medium, memerlukan kecakapan, memerlukan tipe tertentu dari pengetahuan dan selalu berkaitan dengan nilai Potter (dalam Adiputra, 2009).

Potter menjelaskan bahwa konsep literasi memiliki pondasi pada tiga ide dasar. Pertama, literasi media adalah sebuah kontinum, bukan sebuah kategori. Semua orang memiliki pemahamn tentang media, walaupun hanya berbeda tingkatan. Tidak seorangpun yang tidak memahami media dan tidak seorangpun yang benar-benar memahami media dengan lengkap. Sehingga kekuatan perspektif seseorang ditentukan oleh kualitas dari struktur pengetahuannya.

Dari informasi yang berasal dari empat dimensi, yakni kognitif, emosional, estetik dan moral. Dimensi kognitif berkaitan dengan fakta yang terdapat di dalam informasi. Dimensi emosional berisi informasi yang berkaitan dengan perasaan seperti cinta, benci, bahagia, sedih, marah dan sebagainya. Dimensi estetik berkaitan erat dengan apresiasi terhadap pesan dan yang terakhir adalah dimensi moral yang berkaitan dengan nilai. Ketiga, tujuan dari literasi media adalah memberikan control terhadap penafsiran suatu pesan. Pesan memiliki banyak tingkatan makna. Semakin tinggi tingkat literasi media yang dimiliki seseorang, maka semakin banyak makna yang dapat digalinya. Sebaliknya, semakin rendah tingkat literasi media seseorang, semakin sedikit atau semakin dangkal pesan yang didapatnya. Seseorang dengan tingkat literasi media yang rendah akan sulit mengenali ketidakakuratan, memahami kontroversi, mengapresiasi ironi dan satire atau membangun pandangan dunia luas. Seseorang yang memiliki tingkat literasi media yang rendah akan mudah menerima makna yang disodorkan oleh media begitu saja tanpa melakukan refleksi kritis lebih lanjut. 


\section{Metode Penelitian}

Penelitian ini menggunakan metode analisis deskriptif. Metode tersebut dipakai guna menganalisis peran orang tua dalam pendampingan anak-anak digital native, mengidentifikasi dampak dan karakter yang muncul pada anaka-anak digital native dan merumuskan pola pendampingan anak-anak digital native di Rusunawa Sawah Besar Kota Semarang. Data- data primer yang diperlukan diperoleh dari hasil wawancara, pengamatan dan kuesioner terstruktur kepada orang tua-orang tua anak-anak digital native yang akan dijadikan informan. Kriteria informan yang dipilih adalah orang tua yang bekerja diluar rumah dan memiliki anak berusia 10-15 tahun yang dibebaskan memakai ponsel atau smartphone.

\section{Pembahasan}

Penelitian ini membahas tentang bagaimana penguatan peran orang tua dalam pendampingan literasi media anak-anak digital native rusunawa sawah besar kota semarang dalam menumbuhkan karakter kebangsaan. Informan dari penelitian ini adalah para orang tua yang memiliki anak remaja seusia SMP dan SMA yang diperbolehkan membawa dan mengakses media ponsel.

Rusunawa ini beralamatkan di Jl. Sawah Besar, Kaligawe, Gayamsari Kota Semarang. Rusunawa Kaligawe yang terdiri atas tujuh blok mulai dihuni pada 2009, dengan total unit 672. Tiap blok terdiri atas 96 unit. Khusus untuk Blok A, B, dan C terdiri atas empat lantai dengan lantai dasar unit usaha dan tempat parkir. Setiap lantai terdapat 32 unit rumah.

Blok D, E, F, dan G terdiri atas lima lantai dengan lantai dasar digunakan sebagai unit usaha dan tempat parkir, setiap lantainya terdapat 24 unit rumah. Di Rusunawa juga terdapat dua tipe rumah, yaitu tipe 21 dengan luas rumah $3 \times 6$ meter yang berlokasi di Blok A, B, dan C, dan tipe 24 dengan luas $4 \times 6$ meter di Blok D, E, F, dan G. biaya sewa rusunawa tersebut adalah Rp. 75.000,- - Rp. 150.000,- perbulan sesuai dengan Besarnya tarif unit hunian Rusunawa di Semarang per bulan diatur dalam Perda No 3/2012 tentang Sewa Rumah Susun dan Rumah Sewa milik Pemkot serta Perda No 7/2009

Warga yang berhak menempati RUSUNAWA adalah Warga Negara Indonesia yang berdomisili dan bekerja di Wilayah Daerah (Semarang) berpenghasilan rendah dan belum memiliki rumah / tempat tinggal tetap. Warga wajib memenuhi persyaratan administrasi sebagai berikut :

a. mengajukan permohonan secara tertulis kepada pengelola dengan melampirkan :

1. Fotokopi KTP Suami/Istri;

2. Fotokopi Surat Nikah;

3. Fotokopi Kartu Keluarga;

4. Pasfoto suami/istri ukuran 4 x 6 sebanyak 2 (dua) lembar;

5. Surat keterangan tidak memiliki rumah dari Kepala Desa / Kelurahan tempat asal;

6. Surat keterangan penghasilan; 


\section{Surat Keterangan Catatan Kepolisian (SKCK).}

b. menandatangani perjanjian sewa menyewa.

\subsection{Data informan}

Informan dari penelitian ini adalah Orang tua Gimah. Orang tua ini merupakan representasi dari para orang tua yang memiliki anak remaja seusia SMP di Rusunawa Sawah Besar Kota Semarang.

\subsection{Data Hasil Penelitian}

4.2.1. Peran Orang tua dalam mendampingi anak-anak digital native dalam menggunakan gadget/ ponsel Rusunawa sawah besar kota semarang tergolong rusunawa yang cukup besar yang terdiri dari 9 blok dan terbagi dalam 3 RT. Keadaan kehidupannya pun terlihat sangat ramai. Setiap sore banyak anak-anak yang bermain dan berolah raga di Play Ground. Anak-anak remaja tersebut juga terlihat membawa ponsel dan bercakap-cakap dengan temannya.

Warga rusunawa merupakan warga yang sangat heterogen dengan pendapatan ekonominyapun juga berbeda-beda. Rata-rata, keluarga yang tinggal di rusunawa sawah besar kota semarang, kedua orang tuanya bekerja. Dalam pengumpulan data ini, kebanyakan orang tua yang telah memiliki anak remaja bekerja sampai pukul 17.00-18.00. walaupun ada juga orang tua rumah tangga yang tidak bekerja diluar rumah.

Melihat kondisi diatas, peran seorang orang tua dalam hal pendampingan anak-anak remaja ternyata tetap mereka lakukan. Hasil penelitian ini mendapatkan data bahwa orang tua-orang tua tersebut tetap mendampingi anak-anak mereka dengan cara mengawasi apa saja yang mereka lakukan dengan gadget/ ponsel tersebut. Pengawasan tersebut juga mereka lakukan dengan cara bertanya apa saja yang mereka lakukan dengan gadget mereka. Biasanya anak-anak malah akan bercerita banyak dan menunjukkan kabar apa saja yang mereka peroleh dari media tersebut.

Peran pendampingan orang tua pun terlihat dari pembuatan kesepakatan-kesepakatan yang mereka buat dengan anak-anak mereka. Seperti yang disampaikan salah satu informan bahwa dia membolehkan anaknya membawa gadget tetapi prestasi sekolah tidak menurun. Para orang tua juga membatasi akses gadget. Mereka diperbolehkan mengakses gadget setelah sekolah usai.

4.2.2. Karakter-karakter yang muncul pada anak-anak digital native di Rusunawa Sawah Besar Kota Semarang 
Karakter merupakan sikap yang muncul karena pola kepengasuhan dan pendidikan yang anak dapatkan dalam proses perkembangannya. Karakter yang muncul dari anak-anak digital native di rusunawa sawah besar kota semarang cenderung lebih terbuka. Para anak tersebut sering memperlihatkan kepada orang tua mereka apa saja yang mereka dapat dari gadget mereka. Anak- anak menyampaikan status temantemannya dan bahkan status orang tua-orang tua lain yang tinggal dirusunawa sawah besar kepada orang tua dan adiknya. Hal ini terjadi disalah satu informan karena orang tua herman, informan tersebut, memang tidak mempunyai gadget.

Kecenderungan anak-anak digital native yang bersikap lebih terbuka, membuat komunikasi antara orang tua dan anak lebih intensif. Orang tua dapat mengawasi dan mengarahkan anak-anaknya dalam penggunaan gadget mereka. Hubungan antara orang tua dan anakpun menjadi lebih hangat dan dekat.

Karakter lain yang muncul adalah sikap bertanggung jawab. Salah satu informan menyatakan bahwa anak mereka mempunyai gadget dari hasil tabungan mereka sendiri. Hal tersebut ternyata mempengaruhi cara anak tersebut menjaga dan memakai gadget tersebut. Dia lebih berhati-hati dalam memanfaatkan gadgetnya.

\section{Simpulan}

Peran Orang tua dalam mendampingi anak-anak digital native dalam menggunakan media/ ponsel dalam hal pengawasan, pembuatan kesepakatan2, dan pendampingan ttg materi apa saja yang diakses oleh anakanak. Karakter-karakter yang muncul pada anak-anak digital native di Rusunawa Sawah Besar Kota Semarang menjadi bertanggung jawab, terbuka, komunikatif.

\section{DAFTAR PUSTAKA}

Adiputra, Wisnu Martha. 2006. Menyoal Komunikasi Memberdayakan Masyarakat. Yogyakarta. Fisipol UGM

Astuti, Sandi Indra. 2007. Media Literacy: Memerdekakan Khalayak dari Kapitalisme. Bandung. Jurnal Issue (Jurnal ISKI Bandung) Vol 1 No.1 Agustus 2007

------- 2005. Mendidik Masyarakat Cerdas di era Informasi. Dalam Jurnal Etos, Volume I/Th.I/2005

Awaludin, wahyu. Fenomena Generasi Digital Native 25 November 2009 http://www.kompasiana.com/wahyu.awaludin/fenomena-generasi-digitalnative_54ff29aaa333110f4550fc2b.

Baran, Stanley J. 2003. Introduction to Mass Communication: Media Literacy and Culture (3rd edition). New York. McGraw-Hill.

Berger, Arthur Asa. 1998. Media Research Techniques (2nd edition). London: SAGE Publications.

Fardiah, Dedeh. 2009. Hegemoni Pasar Tayangan Anak-anak di Televisi. Unpad Press. Bandung

Copyright (C2018, ISSN: 2598-3040 online 
Lie, Anita. Media, Sentra ke 4 Pendidikan (artikel dalam HU Kompas edisi Selasa, 7 September 2004, hal. 4- 5).

Livingstone, Sonia. The Changing Nature and Uses of Media Literacy. Diakses dari www.lse.ac.uk/collections/media@1se/mediaWorkingPaper/ewpNumber4. Tanggal akses terakhir 16 Juli 2012

Lull, James, 2011. Media, Komunikasi, Kebudayaan : Suatu Pendekatan Global. Jakarta : Yayasan Obor Indonesia

Masduki dan Nazaruddin, Muzayin. 2008. Media, Jurnalisme dan Budaya Populer. Yogyakarta. UII Press

Mosco, Vincent. 1996. The Political Economy of Communication: Rethingking and Renewal. London. Sage Publications

Potter, W. James. 2004. Theory of Media Literacy: A Cognitive Approach. London. Sage Publication.

Prihandini, Isti. 2007. Pelajaran Media Literacy dan Kemampuan Melek Media. Jurnal Thesis Departemen Ilmu Komunikasi FISIP Univesitas Indonesia Volume VI/No.3 September-Desember 2007

Sudibyo, Agus. 2009. Ekonomi Politik Media Penyiaran. Yogyakarta. LKiS Sunarto. 2009. Televisi, Kekerasan dan Perempuan. Jakarta. Kompas Media Nusantara

Suryadi, Israwati. Kajian Perilaku Menonton Tayangan TV dan Pendidikan Literasi Media Pada Remaja . Jurnal Academika Fisip Untad: Vol 5,No 01 Peb 2013.

Triputra, Pinkey. 2004. Dilema Industri Penyiaran di Indonesia: Studi tentang Neoliberalisme dan Perkembangan Pertelevisian di Era Orde Baru dan Reformasi. Disertasi. Jakarta. Universitas Indonesia 